\title{
Challenges of Group-based Micro and Small Enterprises Performance: Evidences from Woreda Fourteen of Kolfe Keranio Sub-City, Addis Ababa, Ethiopia
}

\author{
Tolasa Tafa Wami \\ Lecturer, Department of Management, school of leadership and Governance, Oromia State University
}

\begin{abstract}
The main objective of this study was to investigate the challenges group-based of MSEs performance (construction, manufacturing and service enterprises) in the Woreda 14 of Kolfe keranio Sub city. Unemployment and low income are very common and remain challenging in urban and cities of Ethiopia. Thus, government of Ethiopia has formulated policies that mitigate the overwhelmed problem by fostering micro and small enterprises. To this end, descriptive design and mixed research approach were applied. Both primary and secondary sources of data were collected using questionnaires, interview and document analysis. Primary data were collected from 80 owners and 76 employees of MSEs whereas secondary data were collected from Woreda 14 MSEDO, Kolfe keranio Sub city MSEDO, and Addis Ababa MSE Development Bureau. These collected data were analyzed using simple descriptive statistics and narration to come up with valid and reliable conclusions. The finding of the study shows that various factors that affect the startup, operation and sustainability of MSEs Woreda 14 of Kolfe Keranio sub city. Lack of working place, credit, facility, market and lack of adequate supply of inputs were restricted the operation/performance and success of MSEs. Likewise, lack of premise tax, market, and finance were enforced the owners/mangers to dissolve the enterprises. Moreover, bankruptcy, disagreement between members, complex government rules, regulations, and procedures highly affect the sustainability of MSES. Identifying enterprise need and problem during start-up and operation, encouraging educational status of operators, modernizing working procedure, promoting micro finance institution, encouraging the culture of saving, providing working premises in the appropriate place, and etc. should be recommended to reverse the situations of MSEs.
\end{abstract}

Keywords: Challenges, Micro and Small Enterprise, performance, Kolfe Keranio, Woreda 14 and Addis Ababa. DOI: $10.7176 / \mathrm{JAAS} / 61-04$

Publication date: February $29^{\text {th }} 2020$

\section{Chapter One: Introduction}

\subsection{Background of the Study}

Today in developing countries micro and small enterprises become very important in improving the overall economic growth and development. It also plays a tremendous role in strengthening economy, utilizing local resources, and satisfying vital needs of large segment of the population with their products; enhance technological, marketing and management capacity and skills through adopting and implementing new technologies (FeMSEDA, 2004).

In Ethiopia Micro Small Enterprises is second largest sector in generating employment opportunities next to agriculture (CSA, 2005). According to CSA (2005) the sectors contributes $3.4 \%$ of GDP, $33 \%$ of the industrial sector's contribution and $52 \%$ of the manufacturing sector's contribution to the GDP of the year 2001. In spite of the enormous importance of the micro and small enterprise sector to the national economy in creation of job opportunities and the alleviation of abject poverty in Ethiopia, the sector is facing financial challenges, which impeded its role in the economy. Amongst, lack of access to credit, insufficient loan size, delay to give loan and absence of collateral are some the major challenges that affect the expansion of micro and small enterprises (Wolday and Gebrehiwot, 2006). Moreover, although MSEs, as compared to their larger counterpart businesses, can create more employment per unit of scarce capital, there are many MSEs which dissolve after a short period of time of their establishment rather than growing. Their dissolution will result in a vicious circle in that they won't be able to take owners out of unemployment, poverty, and economic growth remains weak as the dissolution of an established MSEs is a cost to both regional as well as national level governments. Therefore, this study aimed at assessing the challenges of group-based Micro and Small enterprises performance in Woreda 4, Kolfe keranio sub city.

\subsection{Statement of the problem}

Currently micro and small enterprises plays tremendous roles to accelerate the economy of developing countries. It has seen as the engines of employment, alleviating poverty and upgrading the standard of living of citizens (Belay kinati et al.., 2015). However, in developing countries including Ethiopia entrepreneurial activities and the associated Micro and Small Enterprises are particularly salient among the urban poor mainly due to various 
challenges. For instance the international workshop that conducted on the role of MSEs in the economic development of Ethiopia conducted in Addis Ababa in May 2004 shows that MSEs in Ethiopia are facing varieties of difficulties like lack of access to start up and operating capital, lack of working premises both for production and sales, shortage of managerial skills and expertise, inadequate of supply of raw materials and marketing problems (FeMSEDA, 2004).

Moreover, most developing countries like Ethiopia face a wide range of constraints and they are often unable to address the problems they face on their own-even in effectively functioning market economies. The constraints relate amongst others to; policy and institutional environment, access to finance and market, business premises, acquisition of skills, lack of raw materials and lack of infrastructure (ECA, 2011).

Recently, Government of Ethiopia has adopted poverty reduction strategies that mainly emphasize on promotion of micro and small scale enterprises as a major way to reduce poverty. The efficacy of such interventions, however, depends on identifying the key challenges confronting these businesses. However, still the sectors are not performing up to the expectations of many stakeholders. Therefore, conducting this research seems essential in the light of addressing different problems centered in this sector. This study has made an effort to identify challenges of group-based MSEs performance in woreda 14 of Kolfe Keranio sub city of Addis Ababa City and forwarded possible solutions to the policy makers and business operators.

\subsection{Objectives of the study}

\subsubsection{General Objective}

The overall objective of the study was to assess the challenges of group- based micro and small enterprises performance in Woreda 14 of Kolfe Keranio sub-city of Addis Ababa.

\subsubsection{Specific Objectives}

The specific objectives of the study were to:

* To assess the current status of micro and small scale enterprises in the study area.

* To identify the major challenges facing the MSEs performance in identified sectors

\subsection{Research Question}

The study was attempted to answer the following basic questions:

* What is the current status of Micro and Small Scale enterprises

What are the challenges faced the MSEs performance in the identified sectors?

\section{Review of the Related Literature}

\subsection{Theoretical Literature}

In this section, issues like definition and constraints faced in Ethiopian of micro and small enterprises (MSEs) in employment creation and income generation are discussed.

\subsubsection{Definition of Micro and Small Enterprise}

The definition and types of micro and small enterprises differ from country to country and there is no universally stated definition for micro and small enterprises. Depending on their realities and objectives, each country has to establish its own definition for them. For instance, in our country, Ethiopia, micro and small enterprises are given different meanings at different times. The recent applicable definition is given by Central Statics Agency (CSA), 2010, on the bases of criteria -level of paid-up capital/total asset, number of employed workers, and excluding building and the definition divides enterprise between industry and service. The definition takes into consideration of next five year inflation and value of birr. Accordingly, the definition of MSEs is presented as follows.

\section{Micro Enterprise}

* Industry sector (manufacturing, construction, and mineral): An enterprise said to be micro when number of human resource employed is five including owners and owner's family and their capital is less than or equal to $\$ 6000$

* Service ( Retailer, transport, hotel tourism, ICT service):In service sector, human resource employed is five including owners and owners' family and their capital is less than or equal to $\$ 3000$

\section{Small Enterprise}

* Industry sector (manufacturing, construction, and mineral): In small enterprise, number human resource employed is between6-30 and total asset in cash is less than or equals to $\$ 90,000$.

* Service (Retailer, transport, hotel tourism, ICT service): Human resource employed is between6-30 and total asset in cash is less than equals to $\$ 30,000$.

MSEs are defined in most countries based on the number of employees. Accordingly, most commonly, micro enterprise is enterprises with ten and less employees, while small enterprise is enterprises with 10 to 50 employees (Farbman and Lessik, 1989).So, according to their purpose and intention, different countries defined micro and small enterprises differently. However, the parameters generally applied by most countries, single or 
in combination are: capital investment in plant and machinery, number of workers employed, or volume of production or turnover of business (Endalsasa Belay, 2012)

Generally, there are qualitative, comparative, and quantitative criteria to defined micro and small enterprises. The qualitative sides include: their financial practices, training styles, internal management structure, and decision making process. The comparative factors have to do with the way micro and small enterprises are studied vis-à-vis large enterprises in the corporate sector. They are small sized in comparison with the large entities in which they share a given economic space. Whereas the quantitative criteria include: number of workers, sales turn over and investment capital. So that, micro and small enterprises come in varying sizes and in one country may be larger than the „big companies in another. (Besides to definition discrepancies (difference) in different countries, the nomenclature (name) of the sector varies from one country to the other. Countries named the sector as Small-Scale Industries (SSI), Micro and Small Enterprise (MSE), Small and Medium Enterprise (SME) (Ibid).

Enterprises are usually divided in to four levels: micro, small, medium, and large. The definition varies from country to country based on the level of economic development of the country. Classifying enterprises in the above four category can be based on a firms assets, or number of employees. Accordingly, an enterprise considered small in one country may be medium or micro in other country (Taye, 1997).

\subsubsection{Constraints faced MSEs in Ethiopia}

Theoretically, different constraints which hinder the operation of enterprises may exist. Even though, the MSE Sector has vital contribution to the Ethiopian economy, it is not operating without problems. There are different challenges that impede or hinder the operation of micro and small enterprises. As cited in Endalsasa Belay (2012), the major challenges that hinder the operation of the sector mostly associated with, problem related to market: - market is necessary to purchase raw material inputs and to sell products or out puts. Mostly Ethiopian micro and small enterprises faced the problem of access to market. Constraint related to finance: it is clear that finance is very necessary to start and expand business activities. Like lack of market, Ethiopian micro and small enterprises faced with lack of capital during and after establishment. Problem related to Technology: It is clear that using appropriate technology is necessary to increase the quality as well as the quantity of products of business activity. With regard to this, researchers explained the existence of problems in micro and small enterprises in relation to technology. Problems related to infrastructure: It is understandable that good infrastructure facilities (such as road, electric) increase the performance of business activities. On the contrary, poor infrastructure facilities weaken the performance of business activities. Problem related to access to information: Information about identifying the type of activity with the necessary inputs, market information, regulation and legislation, accounting, managerial advice, interlink age information, and etc., is very important for micro and small enterprises to be successful.

Therefore, in order to increase the capacity of the MSE sector and thereby their performance to these real and other related challenges or constraints should be solved or at least minimized.

\section{Research Methodology}

\subsection{Research Design}

The descriptive research design was used to conduct the study. It was selected for the reason that it enables the researchers to obtain current information about the problems that hinders performance of group- based MSE. The method was also relevant to collect detailed and a variety of data concerning the issue under study.

\subsection{Source and Type of Data}

To conduct the study both primary and secondary sources of data were collected and used. Since the study was aimed at examining problems or challenges that hinders performance of group- based micro and small enterprise; the researcher uses with reference from study place. Moreover, quantitative and qualitative data were used to answer research questions.

\subsection{Target Population}

The target population for this descriptive study was micro and small enterprises of Woreda 14, Kolfe Keranio sub-city with the population of 113 enterprises. The focuses of this study were owners, managers and employees of MSEs.

\subsection{Sample Size Determination}

Study applied a simplified formula provided by C.R. Kothari (1990) in order to determine the required sample size of population from which a sample is to be drawn does not constitute a homogeneous group, stratified sampling technique was generally applied in order to obtain a representative sample of Woreda 14 of Kolfe Keranio Sub-city group-based MSE. Questions are highly relevant in the context of stratified sampling according to Kothari as:How many items be selected from each stratum or how to allocate the sample size of each stratum? 
Regarding this question, we usually follow the method of proportional allocation under which the sizes of the samples from the different strata are kept proportional to the sizes of the strata. That is, if Pi represents the proportion of population included in stratum $\mathrm{i}$ and $\mathrm{n}$ represents the total sample size, the number of elements selected from stratum $\mathrm{i}$ is nix $\mathrm{Pi}$

$\mathrm{n}_{1}=\mathrm{nxp}_{1} \quad=\quad$ Where $\mathrm{n}$ is assumed sample

$=\mathrm{n}_{1}$ is sample size we want from each stratum

$=\mathrm{P}_{1}$ is the proportion of population

$\mathrm{p}_{1}=\mathrm{n} \times(\mathrm{N} 1 / \mathrm{N}) \quad=\mathrm{n}$ is assumed sample size,

$=\mathrm{N}_{1}$ is number of strata one from the total population

$=\mathrm{N}$ is total population

\subsubsection{Sampling Techniques/Procedures}

Source: $\quad$ (C.R. Kothari (1990))

Sampling technique is one of the components of research methodology. In the study area, there is about 113 groups- based micro and small enterprises, out of which these 15 were service sectors, 16 were manufacturing industries, and 82 were construction. Among these group-based MSEs, 38(33.33\%) of them were formed in partnerships, whereas 76(66.67\%) of the enterprises were formed in Cooperatives. From these different sectors or each stratum, the sample has been selected through proportional stratified sampling by using previously mentioned formula. This was for the purpose of knowing problems of different sectors of MSEs.

Table 3.1: Population Strata of Group-based Enterprise and members of owners

\begin{tabular}{|l|l|l|l|}
\hline No & Enterprise Sector name & Enterprise number & Owners 'of enterprise \\
\hline 1 & Construction & 82 & 497 \\
\hline 2 & Manufacturing & 16 & 124 \\
\hline 3 & Service & 15 & 117 \\
\hline & Sum & 113 & 738 \\
\hline
\end{tabular}

Source: Kolfe Keranio Woreda 14 MSEDO 2015

Sample taken as:

The researcher want to have a sample of size $n=40$ depend on time and cost to be drawn from a population of size $\mathrm{N}=113$ which is total enterprise in the Woreda 14. With strata of size $\mathrm{N} 1=82$ strata of construction, $\mathrm{N} 2=$ 16 strata of manufacturing, and N3=15 strata of service. Adopting proportional allocation, the researcher got the sample sizes as under for the different strata: For

$$
\text { Strata with } \mathrm{N} 1=82 \quad \mathrm{n} 1=\mathrm{nxP} 1=40(82 / 113)=29
$$

For strata with $\quad \mathrm{N} 2=16 \mathrm{n} 2=\mathrm{n} \times \mathrm{P} 2=40(16 / 113)=6$

For strata with $\quad \mathrm{N} 3=15$, we have $\mathrm{n}=\mathrm{n} \times \mathrm{P} 3=40(15 / 113)=5$

Therefore, the formula was used to allocate proportional sample from each strata as:

Sample1 $=29$ from construction sector

Sample $2=6$ from manufacturing sector

Sample $3=5$ from service sector

For each enterprise included in sample, two samples were taken one for owner of the enterprise and the other for employees of enterprises. For the owner of the enterprise sampling technique has been used, in which purposively two enterprise owners have randomly selected to express their enterprise situation as a whole. The other sample taken was for employees. The employees of enterprise were selected and this was 20 percent of employees was taken through probability/ simple random/ method from the each three type of enterprise.

Table 3.2: Sample enterprise, sample enterprise owners and employees of enterprise (unit of analysis) are presented as follows

\begin{tabular}{|c|c|c|c|c|c|c|}
\hline Enterprise & $\begin{array}{l}\text { No. of } \\
\text { Sampled } \\
\text { enterprise }\end{array}$ & $\begin{array}{l}\text { Total } \\
\text { enterprise } \\
\text { owner }\end{array}$ & $\begin{array}{l}\text { No. of } \\
\text { sampled } \\
\text { Enterprise } \\
\text { owners) }\end{array}$ & $\begin{array}{l}\text { Total } \\
\text { employees in } \\
\text { sampled } \\
\text { enterprise }\end{array}$ & $\begin{array}{ll}20 \% \text { of } & \text { total } \\
\text { employees } & \text { was } \\
\text { sampled } & \\
\text { enterprise } & \\
\end{array}$ & $\begin{array}{l}\text { Unit of } \\
\text { analysis }\end{array}$ \\
\hline Construction & 29 & 188 & 58 & 260 & 52 & 110 \\
\hline Manufacturing & 6 & 56 & 12 & 100 & 20 & 32 \\
\hline Service & 5 & 50 & 10 & 22 & 4 & 14 \\
\hline Total & 40 & 294 & 80 & 382 & 76 & 156 \\
\hline
\end{tabular}

Source: Own survey, 2015

Generally, 40(35\% of total population of enterprise) group-based enterprise were proportionally, included in sample through stratified random sampling where as 156 operators (owners and employees) of enterprise or around 23\% (sample of owners 294 and employees 382) of total population included in sample were taken randomly from the sample enterprise. 
In-depth interviews would be conducted by taking samples of two MSEs from each type surveyed sectors disproportionally and two employees from sampled MSEs sector. These interviews with sample respondents were undertaken believing would help the researcher find out necessary information. Similarly, officials of the MSEs support office would be interviewed on the issues of constraints and sustainability of the MSEs.

\subsection{Methods of Data Collection}

Data were collected using self-administer questionnaires, interviews and document analysis or document review. Data regarding the problems of MSEs in woreda 14, of Kolfe Keranio sub-city of Addis Ababa has been collected through structured questionnaires from owners, managers and employees of the enterprises. Data which was difficult to obtain from owners and employees of enterprise through questionnaires were collected by using interview to supplements and triangulate the findings of the study. Additionally; secondary data sources were collected from both published and unpublished documents, reports, journals articles and other related books

\subsection{Method of Data Analysis}

The data which collected from target population were analyzed by using descriptive method of data analysis. Specifically the statistical techniques like frequency, percentages and averages were used to organize and present data by using tables. Furthermore, quantitative as well as qualitative data analysis methods were applied to analyze the information gathered through interviews and document analysis or review.

\section{Results and Discussion}

\subsection{The current Status of Enterprise}

Capital formation and employment opportunities determine the current status and trends of micro and small scale enterprises (MSEs). The information about the enterprises illustrates that $60 \%$ of enterprises were small scale enterprises followed by micro scale enterprises that accounts $22.5 \%$ and the rest $10 \%$ of enterprises were above micro and small scale enterprises. This suggests that the majority of the enterprises that operate in Worde 14 of Kolfe keranio sub city are small scale enterprises followed micro scale enterprises.

Figure 1: Status of the Enterprises

\section{Proportion of Enterprise Status}
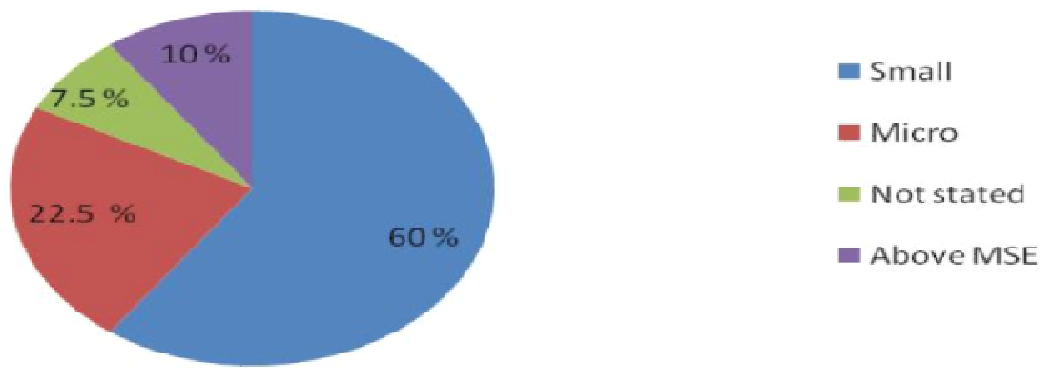

Source: own survey, 2015

The status of the enterprises is changing from time to time as its capital and workers are increasing. For instance in Woreda 14 of Kolfe keranio sub city around $37.5 \%$ of manufacturing sector was graduated and jumped to small scale enterprises due the existence of high experience and partner ownership structure. Similarly 23 of construction, 6 of manufacturing and 4 of service enterprise were graduated and jumped to small enterprises at the age of more than five years. However, the graduation of micro and small scale enterprises affected by lack of selling place, lack of infrastructure, lack of experience sharing from other successful (graduated) enterprises, and reluctance of the members to work together in collaboration with their fellow members and in partnership with other MSEs. Correspondingly bureaucratic bottlenecks, poor implementation capacity of workers, weak institutional structures, lack of commitment among the officials and their subordinates, absence of training and poor monitoring and controlling were hindered the graduation time of the enterprises.

\subsection{The Mian Challenges of MSEs}

\subsubsection{Startup Problem of Owner's Enterprises}

As explained in literature part of this research, MSE in Ethiopia as well as in Addis Ababa, like many other developing countries, had faced many constraints like access to credit facility and work place. Therefore, owners/managers participation in economic activities, generally, and in self-employment, specifically, is limited. 
As Table 1 shows, $21.25 \%$ of problem of owners to be self-employed was the lack of infrastructures, disagreement between members, and credit facility. The second obstacle for owners/managers $(20 \%$ of respondents) was the lack of working place, supplies and disagreement between members. About $16.25 \%$ of the owners responded that being challenged by lack of infrastructures, credit facility and procedures of registration. Only $6.25 \%$ of the total owners reported that procedures of registration were a major difficulty for them. For $16.67 \%$ manufacturing sector registration process was difficult problem at startup. $10.34 \%$ of construction enterprises said do not satisfy with infrastructure, which obstacle them not to be engaged in MSEs.

Lack of skill about enterprise, and procedures of registration that helps owners/managers to participate in economic activities were the important problems for them. $10 \%$ of service enterprise owner/managers respond registration procedure is difficult problem for them. For 40 percent of the service owners, accesses to working place, supplies and disagreement between members and for manufacturing 33.33 percent infrastructure, disagreement between members, and credit facility were the important problems.

Market shortage was only least problem encountered all owners/managers during startup. And majority of manufacturing and service enterprise owners/managers were identified more than two problems at startup. Generally, problems encountered enterprise during startup is different from sector to sector even in the similar sector faced different constraints at same time i.e. at startup time.

Table 1: Startup problems of MSEs

\begin{tabular}{|c|c|c|c|c|c|c|c|c|}
\hline \multirow[t]{3}{*}{ Startup problems of MSEs } & \multicolumn{8}{|c|}{ Types of Enterprise } \\
\hline & \multicolumn{2}{|c|}{ Construction } & \multicolumn{2}{|c|}{ Manufacturing } & \multicolumn{2}{|c|}{ Service } & \multicolumn{2}{|c|}{ Total } \\
\hline & Freq. & $\%$ & Freq. & $\%$ & Freq & $\%$ & Freq. & $\%$ \\
\hline Lack of working place(1) & 3 & 5.2 & - & & - & & 3 & 3.75 \\
\hline Supplies (2) & 5 & 8.6 & & & - & & 5 & 6.25 \\
\hline Market shortage(3) & 3 & 5.2 & - & & - & & 3 & 3.75 \\
\hline Infrastructure (4) & 6 & 10.34 & 1 & 8.33 & - & & 7 & 8.75 \\
\hline Disagreement between members $(5)$ & 4 & 6.9 & - & & - & & 4 & 5 \\
\hline Credit facility $(6)$ & 3 & 5.3 & - & & - & & 3 & 3.75 \\
\hline Lack skill(7) & 4 & 6.9 & - & & - & & 4 & 4 \\
\hline Procedures of registration(8) & 2 & 3.44 & 2 & 16.67 & 1 & 10 & 5 & 6.25 \\
\hline Variable N0 4,5 \& 6 & 11 & 19 & 4 & 33.33 & 2 & 20 & 17 & 21.25 \\
\hline Variable N0 1,2\& 5 & 9 & 15.5 & 3 & 25 & 4 & 40 & 16 & 20 \\
\hline Variable N0 4,6\&8 & 8 & 13.8 & 2 & 16.67 & 3 & 30 & 13 & 16.25 \\
\hline Total & 58 & 100.0 & 12 & 100.0 & 10 & 100 & 80 & 100.0 \\
\hline
\end{tabular}

Source: own survey data, 2015

4.1.2. Major Constraints of Micro and Small Enterprise during Operation

MSE owners of woreda 14 of Kolfe Keranio sub-city are constrained by a number of problems during the time of operation of their businesses. Accordingly, the survey conducted in woreda 14 on the sample size indicated that owners were constrained with lack of working place, insufficiency of finance or credit facility, inadequate supply of inputs, rules and regulations procedures and paying large taxes according to their severity at the time of business operation (table. 4.2). As shown in table 4.2 owners/ managers of sampled enterprise have identified problems encountered their business during the operation. Respondents in sampled enterprise gave their response, $21.25 \%$ of them total surveyed sample enterprise said lack of working places, credit facility, inadequate supply of inputs and market problem especially for manufacture enterprise (41.67\%). In service sector lack of credit facilities, lack of working place, inadequate supply of inputs and lack market problem were the difficult problem $(40 \%)$ identified by most of the respondents.

Respondents in construction sector said disagreement between members, lack of capacity to compete with similar enterprise, lack of capacity to compete large enterprises and government rules and regulation procedure were about $6.9,8.6,8.6$ and 6.9 percent of the total sample size, respectively (table 4.2). In similar way, owners/managers of service sectors faced problem of market and credit facility were 20 and 10 percent in total sampled sector of the enterprise respectively where identified by few respondents as shown in the below table 2 . Entrepreneurs in construction would have faced a number of constraints. From data collected, we can identify the most constraining problem that made operation difficult.

Similarly around $13.8 \%$ of respondents were identified problems like lack of working place; credit facility and inadequate supply of inputs in construction sector. $40 \%$ of (shortage of market, lack of working place, credit facility and inadequate supply of inputs) were severe problem mentioned by the respondents of service sector. In similar way, manufacturing sector operator responds to asked question in different degree to problem faced their enterprise as market problem, lack of work place, credit facility and inadequate supply of inputs $(41.67 \%)$ were the most problem, most of the respondents suggested. This shows that absence of business enabling environment during time of operation mostly affect the growth and performances of micro and small enterprises. 
Table 2: Major Constraints of Micro and Small Enterprise

\begin{tabular}{|c|c|c|c|c|c|c|c|c|}
\hline \multirow[t]{3}{*}{ Constraints of MSEs } & \multicolumn{6}{|c|}{ Types of Enterprise } & \multirow{2}{*}{\multicolumn{2}{|c|}{ Total }} \\
\hline & \multicolumn{2}{|c|}{ Construction } & \multicolumn{2}{|c|}{ Manufacturing } & \multicolumn{2}{|c|}{ Servie } & & \\
\hline & Freq. & $\%$ & Freq. & $\%$ & Freq & $\%$ & Freq. & $\%$ \\
\hline Lack of working place (1) & 2 & 3.5 & - & - & - & & 2 & 2.5 \\
\hline Insufficiency of finance(2) & 1 & 1.7 & & - & - & & 1 & 1.25 \\
\hline Credit facility(3) & 4 & 6.9 & - & - & 1 & 10 & 5 & 6.25 \\
\hline $\begin{array}{l}\text { Lack of capacity to compete large } \\
\text { enterprises (4) }\end{array}$ & 5 & 8.6 & - & - & - & & 5 & 6.25 \\
\hline Inadequate supply of inputs $(5)$ & 2 & 3.5 & - & - & - & & 2 & 2.5 \\
\hline Market problem (6) & 5 & 8.6 & 1 & 8.33 & 2 & 20 & 8 & 10 \\
\hline Variable No $1,3,5 \& 6(7)$ & 8 & 13.8 & 5 & 41.67 & 4 & 40 & 17 & 21.25 \\
\hline $\begin{array}{lrll}\text { Complex government } & \text { rules } & \text { and } \\
\text { regulations procedures }(8) & & \end{array}$ & 4 & 6.9 & - & - & - & - & 4 & 5 \\
\hline $\begin{array}{l}\text { Lack of capacity to compete similar } \\
\text { enterprise }(9)\end{array}$ & 5 & 8.6 & - & - & - & - & 5 & 6.25 \\
\hline Paying large taxes(10) & 5 & 8.6 & 1 & 8.33 & - & - & 6 & 7.5 \\
\hline Variable N03,5,6,8\& 10(11) & 6 & 10.4 & 2 & 16.67 & 3 & 30 & 11 & 13.75 \\
\hline $\begin{array}{ll}\text { Disagreement } & \text { between } \\
\text { members(12) } & \\
\end{array}$ & 4 & 6.9 & & - & - & - & 4 & 5 \\
\hline Variable N $\underline{0} 1,2,6,8,10 \& 12(13)$ & 7 & 12.1 & 3 & 25.00 & -- & - & 10 & 12.5 \\
\hline Total & 58 & 100.0 & 12 & 100.0 & 10 & 100.0 & 80 & 100.0 \\
\hline
\end{tabular}

Source: own survey data, 2015

Evidence from the above table, shows that insufficiency of finance, lack of working place, and inadequate supply of inputs were reported as the least obstacle identified by few respondents in the three sectors. As it is shown in the above table, the three most common challenging factors faced almost equally by MSEs Owners through operation cycle identified by respondents include lack of market, lack of access to working premise and lack of access to credit facility. So we cannot hopefully conclude that occurrence of problems at operation is the same through sector even within the similar type of sector. To solve this problem effectively it is helpful to identify and know problems according to its harshness.

\subsubsection{Factors Anticipated being Affect Sustainability of MSEs}

There are different factors assured to dissolving of MSEs. Owners/managers enterprises were asked their opinion about the factors contributing for dissolving MSE's in the future. Accordingly, the enterprise owners/managers woreda 14 have respond as $17(21.25 \%)$ of MSE will be dissolved due to problem occurred with lack of premise, tax, market, and finance which is the most common problem in all surveyed sample enterprise with little difference in the degree. 13(16.25\%) of the total respondents expressed their anticipation as their enterprise will be dissolved due to lack of premise, disagreement between members, market and complex government rules and regulations procedures.

The below table indicates, in woreda 14 of Kolfe Keranio sub-city there are variety of reasons anticipated for dissolving MSE's according to respondents of sampled enterprise. Among these, 7 (8.5\%) of them will dissolved due to only large tax payment in their business, $5(6.25 \%)$ of them due to disagreement between members, $4(5 \%)$ of them are due to formality/complex government rules and regulations procedures, and $12(15 \%)$ of them are due to market.

Depend on data collected, the most factors anticipated to dissolve enterprise identified as in construction sector was $17.24 \%$ of them are lack of premise, tax, market, and finance. It also in sampled manufacturing enterprise $33.33 \%$ of them are/due to the same problem occurred in construction sector and it also the same problem in service sectors $30 \%$. Most common least factors anticipated to affect the sustainability of the three MSE's sectors are bankruptcy (5\%), disagreement between members $(6.25 \%)$ and $5 \%$ is complex government rules and regulation procedures (Table 3 ).

By and large enterprise owners anticipated problems dissolve their enterprises' in the future depend on current situation. Their anticipation were not the same in the three enterprise on future problem may they faced. We cannot necessarily conclude that problems they will face is the same or different in the three enterprise even in similar sector. 
Table 3: Factors Contributed to dissolve MSEs in Woreda 14 of Kolfe Keranio sub city

\begin{tabular}{|c|c|c|c|c|c|c|c|c|}
\hline \multirow[t]{3}{*}{ Factors } & \multicolumn{6}{|c|}{ Micro and Small Enterprises } & & \\
\hline & \multicolumn{2}{|c|}{ Construction } & \multicolumn{2}{|c|}{ Manufacturing } & \multicolumn{2}{|c|}{ Service } & \multicolumn{2}{|c|}{ Total } \\
\hline & Freq. & $\%$ & Freq. & $\%$ & Freq. & $\%$ & Freq. & $\%$ \\
\hline Bankruptcy (1) & 4 & 6.9 & - & & - & & 4 & 5 \\
\hline Lack of premise (2) & 7 & 12.1 & 2 & 16.67 & 2 & 20 & 11 & 13.75 \\
\hline Address/sector change (3) & & & & & & & - & - \\
\hline Disagreement between Members(4) & 5 & 8.6 & - & - & - & - & 5 & 6.25 \\
\hline Asset sale (5) & - & - & - & - & - & - & - & - \\
\hline $\operatorname{Tax}(6)$ & 6 & 10.34 & 1 & 8.33 & - & - & 7 & 8.75 \\
\hline Variable No, 2, 6,8, \&9 (7) & 10 & 17.24 & 4 & 33.33 & 3 & 30 & 17 & 21.25 \\
\hline Market (8) & 8 & 13.9 & 2 & 16.67 & 2 & 20 & 12 & 15 \\
\hline Finance (9) & 6 & 10.34 & - & - & 1 & 10 & 7 & 8.75 \\
\hline $\begin{array}{l}\text { Complex government rules and } \\
\text { regulations procedures }(10)\end{array}$ & 4 & 6.9 & - & - & - & - & 4 & 5 \\
\hline Variable No 2, 4, 8and $10(11)$ & 8 & 13.9 & 3 & 25 & 2 & 20 & 13 & 16.25 \\
\hline Total & 58 & 100.00 & 12 & 100.00 & 10 & 100.00 & 80 & 100.00 \\
\hline
\end{tabular}

Source: own survey data, 2015

4.1.4 Capacity to Mitigate the Challenges By Own Selves

When asked to indicate whether they had capacity to mitigating the challenges, majority of the enterprise owners at $41(70.7 \%), 9(75 \%)$ and $7(70 \%)$ indicated that they did take measure to tackle the problems in construction, manufacturing and service respectively, while only construction $17(29.3 \%)$, manufacturing $3(25 \%)$ and service $3(30 \%)$ indicated otherwise. This shows that in most cases, enterprise owners were expect little assistance from the government or the NGOs tackle challenges in Woreda 14 of Kolfe keranio sub-city. During key informative interview the few head of enterprise said they need government support on the area of loan accessibility, market, work premises and offering entrepreneurial and managerial trainings on problems encountered and this could result into quick growth rate in these business activities.

Table 4: Mitigate the challenges By Own selves

\begin{tabular}{|c|c|c|c|c|c|c|c|c|}
\hline \multirow[t]{2}{*}{ Variables } & \multicolumn{2}{|c|}{ Construction } & \multicolumn{2}{|c|}{ Manufacturing } & \multicolumn{2}{|c|}{ Service } & \multicolumn{2}{|l|}{ Tota } \\
\hline & Freq. & $\%$ & Freq. & $\%$ & Freq. & $\%$ & Freq. & $\%$ \\
\hline Yes & 41 & 70.7 & 9 & 75 & 7 & 70 & 57 & 71.25 \\
\hline No & 17 & 29.3 & 3 & 25 & 3 & 30 & 23 & 28.75 \\
\hline Total & 58 & 100.00 & 12 & 100.00 & 10 & 100.00 & 80 & 100.00 \\
\hline
\end{tabular}

Source: own survey data, 2015

The study also sought to find out whether failure to tackle challenges facing the enterprise owners could result into their undermine growth specially those who did not $(28.75 \%)$. Out of the 80 respondents that took part in answering this question, majority at $71.25 \%$ said they mitigate challenges by their own effort without need government or NGOs assistance. By and large, to check reliability and accuracy of information related to problems hinders growth and performance of MSE in study area the head of MSEDO were interviewed. What were the problems of MSEs? Do you think that government sectors shares the problem of group- based MSEs made them not to grow and perform well in given time?

The head of Micro and Small Enterprise office did not deny problem caused from government sectors. This shows that the main challenges of MSE mainly came from government sectors especially from local government. Bureaucratic working procedures and other bottlenecks associated with poor implementation capacity resulting from weak institutional capacity, lack of awareness about or failure to conform with MSE-related policies, strategies and proclamations etc., lack of commitment among the officials and their subordinates, absence of training to MSE extension agents, and poor monitoring and follow-up were some of the challenges of MSEs. This is consistent with interview results. The head of MSEDO indicated that unattractiveness and inadequacy of the salary and absence of other incentive packages, insufficient service and facilities highly hinders the performance and growth of MSEs in Woreda 14 of Kolfe Keranio sub city, Addis Ababa.

\section{Conclusion and Recommendations}

\subsection{Conclusion}

In the study area, status of enterprise was different from enterprise to enterprise that majority of them were small scale enterprises followed by micro scale enterprises and the rest $10 \%$ of enterprises were above micro and small scale enterprises. When status of enterprise was seen individually, construction enterprise was highly jumped into small enterprise from micro enterprises followed by manufacturing enterprise.

The challenges of MSEs, hinders health of economy has long time shocked both in the developed and 
developing countries. Particularly, performance of MSEs towards both employment creations and income generations for the large sections of unskilled and semi-skilled labor force in developing countries has stimulated significant interest among policy makers and practitioners alike.

The study shows that enterprise owners/managers had faced different problems during start-up and operation. Lack of market problem, working place, credit, collateral land inadequate supply of inputs were highly hinder the startup and operation of construction, manufacturing and service sectors. Likewise predicting or guessing the future problems will have paramount contribution in the success of the enterprises. Consequently, the survey result identified lack of premise, high tax, in adequate market, and finance could dissolve the construction, manufacturing and service sectors in woreda 14 of Kolfe Keranio sub city.

Moreover, bankruptcy, disagreement between members, and complex government rules and regulation procedures were also affect the sustainability of MSEs. Moreover, bureaucratic working procedures, weak institutional capacity, lack of awareness about or failure to conform to MSE-related policies, strategies and proclamations were hindered performance of MSEs. Accordingly, in study area, enterprise owners/managers had capacity to mitigating the challenges, and they did take measure to tackle the problems in construction, manufacturing and service sectors.

\subsection{Recommendations}

The following recommendations have been drawn, with the view to improve performance of group- based micro and small enterprises.

$>$ The capacity of enterprises' to change their status in given time was different from enterprise to enterprise. In order to improve enterprise capacitating to jump from micro to small and from small to medium should be encourage through training and material support.

$>$ Challenges mainly came from government sector offices at local level like bureaucratic working procedures and others should be eliminated and working procedure should be modernized through implementation of reform programs.

$>$ Enterprise owners faced challenges from startup to operation level; problems encountered enterprises during starting time and operation were different. The then should identify according to their occurrence and immediate solution should be taken. The capacity to anticipate factors affecting the sustainability of enterprise in future will be build.

$>$ Enterprise owners should encouraged and learn how to mitigating the challenges faced them by their own effort with little/no assistance from government or non-government.

$>$ The local government (the woreda and sub city government) has to promote the establishment of other alternative micro finance institutions so as to improve access to credit service for MSEs.

\section{REFERENCE}

Central Statistical Authority (CSA), (2004/5), Report on Small Scale Manufacturing Industries Survey, Government publishing services Addis Ababa

Central Statistical Authority (2010), Analyzed Report on meaning and status of MSEs, Addis Ababa, Ethiopia

Creswell, J.W. (1994). Research Design: Qualitative and Quantitative Approaches. Thousand Oaks. CA: Sage

C.R.Kothari,1990, Research Methodology,2nd, New Age International (P) Ltd., Publishers, Jaipur (India)

Economic Commission for Africa (ECA)(2001). Working document for the workshop on the theme: Enhancing the competitiveness of MSE in Africa: A strategic framework for support services organized by ECA in collaboration with IDEP and the Senegalese Ministry of Industry, 2-5 October 2001, Dakar.

Endalsasa Belay (2012). The Contribution of Group-Based Micro and Small Enterprises to the Local Economy and Social Development in the Arada Sub City: A Case Study on Metal and Wood Work Enterprises, Addis Ababa University

Farbman M. and Lessik A., (1989) .The Impact of Classification on Policy“, in A. Gosses et al. (eds), Small Enterprises, New Approaches. The Hague: Ministry of Foreign Affairs, Directorate of International Cooperation.

Federal microandsmall enterprises development agency (2004).Proceeding of the international workshop on the role of MSEs in the economic development of Ethiopia, Addis Ababa

GebrehiwetAgeba\& Wolday Ameha (2006). Micro and small enterprises finance in Ethiopia. International Journal of Emerging Markets, 1/4, 305-328.

Kothari, C. R. 2004. Research Methodology.Methods and Techniques.(2nd ed). New New Delhi: Age International $(\mathrm{P}) \mathrm{Ltd}$

Taye B., (1997), The reform process and the role of Association in the development of small scale enterprises: In Wolday Amha (1997): Small scale enterprise development in Ethiopia. Proceedings of the six annual conferences on the Ethiopian economy, Addis Ababa. 